\title{
The effect of soy isoflavone on bone mineral density in postmenopausal Taiwanese women with bone loss: a 2-year randomized double-blind placebo-controlled study
}

\author{
T. Y. Tai • K. S. Tsai • S. T. Tu • J. S. Wu • C. I. Chang • \\ C. L. Chen $\cdot$ N. S. Shaw $\cdot$ H. Y. Peng $\cdot$ S. Y. Wang $\cdot$ \\ C. H. Wu
}

Received: 15 October 2010 /Accepted: 21 June 2011 / Published online: 8 September 2011

(C) The Author(s) 2011. This article is published with open access at Springerlink.com

\begin{abstract}
Summary The treatment of 300-mg/day isoflavones (aglycone equivalents) (172.5 mg genistein $+127.5 \mathrm{mg}$ daidzein) for 2 years failed to prevent lumbar spine and total proximal femur bone mineral density (BMD) from declining as compared with the placebo group in a randomized, double-blind, two-arm designed study enrolling 431 postmenopausal women 45-65 years old.

Introduction This study evaluated the effects of soy isoflavones on bone metabolism in postmenopausal women.

Methods Four hundred and thirty-one women, aged 4565 years, orally consumed 300-mg/day isoflavones (aglycone equivalents) or a placebo for 2 years in a parallel group, randomized, double-blind, two-arm study. Each participant also ingested $600 \mathrm{mg}$ of calcium and $125 \mathrm{IU}$ of vitamin $\mathrm{D}_{3}$ per day. The BMD of the lumbar spine and total proximal femur were measured using dual-energy X-ray absorptiometry at baseline
\end{abstract}

\section{T. Y. Tai $\cdot$ C. I. Chang}

Division of Geriatric Research,

Institute of Population Health Sciences,

National Health Research Institutes,

Taipei, Taiwan

\section{K. S. Tsai}

Department of Laboratory Medicine, National Taiwan University Hospital,

Taipei, Taiwan

\section{S. T. Tu $\cdot$ S. Y. Wang}

Division of Endocrinology and Metabolism,

Changhua Christian Hospital,

Changhua, Taiwan

\section{J. S. Wu $\cdot$ C. H. Wu}

Department of Family Medicine,

National Cheng Kung University,

Tainan, Taiwan and every half-year thereafter. Serum bone-specific alkaline phosphatase, urinary N-telopeptide of type 1 collagen/creatinine, and other safety assessments were examined regularly. Results Two hundred out of 217 subjects in the isoflavone group and 199 out of 214 cases in placebo group completed the treatment. Serum concentrations of isoflavone metabolites, genistein and daidzein, of the intervention group were remarkably elevated following intake of isoflavones $(p<$ 0.001 ). However, differences in the mean percentage changes of BMD throughout the treatment period were not statistically significant (lumbar spine, $p=0.42$; total femur, $p=0.39$ ) between the isoflavone and placebo groups, according to the generalized estimating equation (GEE) method. A significant time trend of bone loss was observed at both sites as assessed by the GEE method following repeated measurement of $\operatorname{BMD}(p<0.001)$. Differences in bone marker levels were not significant between the two treatment groups.

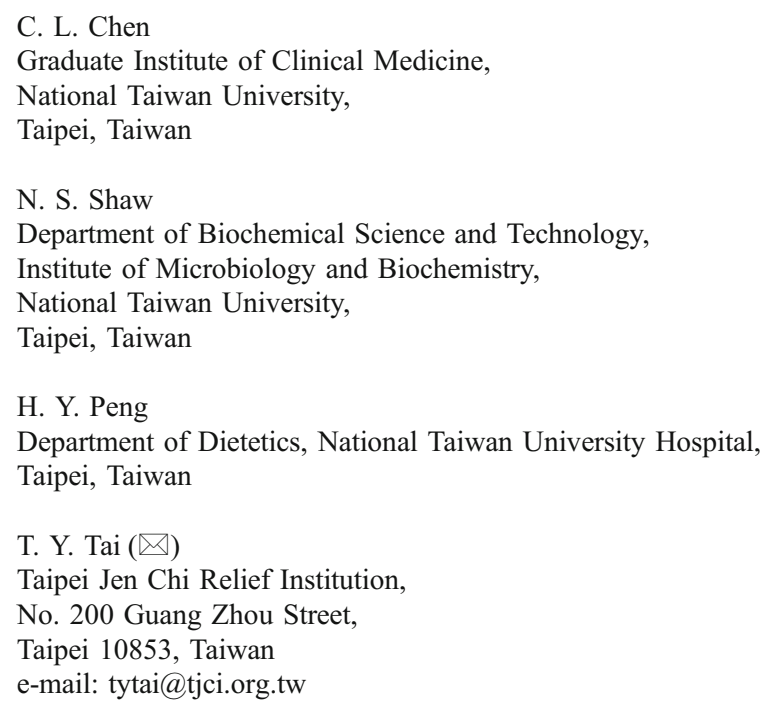


Conclusion Treatment with 300-mg/day isoflavones (aglycone equivalents) failed to prevent a decline in BMD in the lumbar spine or total femur compared with the placebo group.

Keywords Bone mineral density · Postmenopausal women · Soy isoflavone

\section{Introduction}

Estrogen deficiency is regarded as a leading cause of bone loss and osteoporosis in postmenopausal women. Although hormone therapy (HT) in postmenopausal women has been found to be efficacious in mitigating bone loss and preventing bone fractures [1, 2], the results of the recent Women's Health Initiative trial suggest that a combination of estrogen plus progestin taken for more than 5 years may increase the risk of invasive breast cancer and cardiovascular events, including coronary heart disease and stroke [3]. A trial using an estrogen-only arm in hysterectomized women also demonstrated a higher risk of cerebrovascular events [4]. Phytoestrogens exhibit weak estrogenic activity, on the order of $10^{-2}-10^{-3}$ that of $17 \beta$-estradiol $[5,6]$. The three major chemical types of phytoestrogens that have been identified are isoflavones, lignans, and coumestans. The primary isoflavones in aglycone form are genistein, daidzein, and glycitein. They are found in soybeans and have been considered by some, but not all, researchers as potential alternatives to HT [7]. When the study was first planned in mid-2003, many investigations evaluating the effects of isoflavone-containing soy protein or isolated isoflavones on bone health of peri-menopausal or postmenopausal women had already been published. Only a few of those studies were double-blind, randomized, placebo-controlled trials [8-12]. They were characterized by small sample size ( $\leqq 175$ cases), short-term duration ( $\leq 12$ months), and low daily dose ( $\leqq 99 \mathrm{mg}$ aglycone equivalents). The parameters observed were bone mineral density (BMD) and/or bone turnover markers, and the results were inconsistent. In an attempt to better understand the effects of soy isoflavones on bone health, this study was designed to examine the effects of soy isoflavones on BMD of Taiwanese postmenopausal women with bone loss, employing a larger sample size, a higher dose of isoflavone, and a follow-up of longer duration.

\section{Methods}

\section{Study design}

This study was designed as a 2-year, parallel group, placebo-controlled, double-blind, two-arm clinical trial conducted simultaneously at three medical centers in
Taiwan: the National Taiwan University Hospital (NTUH), Changhua Christian Hospital $(\mathrm{CCH})$, and National Cheng Kung University Hospital (NCKUH). Each center has recruited 144, 142, and 145 participants, respectively. Because previous studies indicated that an intake of $40-\mathrm{g} /$ day soy protein containing 90-mg isoflavones for 6 months increased lumbar spine BMD by $2.2 \%$ [8] and 54-mg genistein/day for 12 months induced a 3\% gain in BMD at proximal femur and spine [10], it was postulated that with a standard deviation of $4.0 \%$ in the distribution of treatment responses, 50 participants per arm could reach over $80 \%$ statistical power to detect a $2.5 \%$ difference in mean percentage change in BMD in lumbar spine between the treatment and placebo groups (with a significance level of $5 \%$ ). We anticipated a $20 \%$ dropout rate, recruiting no fewer than 140 subjects at each center.

\section{Inclusion criteria of participants}

We enrolled 431 Taiwanese postmenopausal women with the following criteria: aged $>45$ and $<65$ years; cessation of menses for at least 12 months and less than 10 years; lumbar spine at second, third, and fourth lumbar vertebrae (L2-L4) BMD 1 SD below the young adult female mean value (T-score $<-1$ ); BMI $18.5-30 \mathrm{~kg} / \mathrm{m}^{2}$; folliclestimulating hormone $(\mathrm{FSH})>40 \mathrm{IU} / \mathrm{L}$; and estradiol $\left(\mathrm{E}_{2}\right)$ $<40 \mathrm{pg} / \mathrm{mL}$. The exclusion criteria were clinical or laboratory evidence of systemic disease; presence or history of vertebral, hip, or wrist fractures; other metabolic bone diseases; gynecological cancer; breast cancer; cervical smear result of class III or IV based on the Bethesda system; undiagnosed vaginal bleeding; significant or pathological endometrial hyperplasia; known cardiovascular, cerebrovascular, or peripheral vascular disorder; poorly controlled diabetes with $\mathrm{HbA} 1 \mathrm{c} \geq 10 \%$; uncontrolled hypertension with blood pressure $\geq 180 / 100 \mathrm{mmHg}$; uncontrolled hypothyroidism; abnormal liver function with alanine aminotransferase (ALT) and aspartate aminotransferase (AST) values $>2$-fold upper limits, or renal disease with serum creatinine $>2 \mathrm{mg} / \mathrm{dL}$; the use of HT, selective estrogen receptor modulators, or phytoestrogen treatment within the previous 3 months; the use of fluoride, calcitonin, chronic systemic corticosteroid, or any other treatment affecting BMD within the previous 6 months; or any use of bisphosphonate within the previous 12 months, or an accumulative usage of any bisphosphonate for more than 3 months before the previous 12 months (the only available bisphosphonate in Taiwan is weekly alendronate). For those who had undergone hysterectomy, the age had to have been 50 to 60 years, with $\mathrm{FSH}$ and $\mathrm{E}_{2}$ concentrations as previously stated. All eligible healthy postmenopausal women were recruited between December 2004 and January 2006. They provided written informed consent 
prior to participation in this study. The study protocol was approved by local and national ethics committees in accordance with the Declaration of Helsinki and Good Clinical Practices Guidelines. Based upon the reports of poor effect of daily doses of 118 [13], 150 [14] and $114 \mathrm{mg}$ [15] of isoflavone for alleviating postmenopausal vasomotor symptoms, and the possibility that inquiring about hot flash symptomatology might increase the withdrawal rate, hot flash data were not collected in this study.

\section{Allocation of participants}

Eight hundred thirty-seven potentially eligible women were invited to undergo the screening examinations. Among the 435 eligible cases, 431 cases were randomized into the isoflavone treatment group or the placebo group (Fig. 1). We obtained a randomization code for each participant using the permuted randomization method with a block size of eight within each center. For each center, random codes for isoflavone or placebo were evenly generated. Each randomization number was assigned to an individual subject according to the time sequence of the subject becoming eligible. Each eligible case was randomized to one of the two treatment groups in a 1:1 ratio

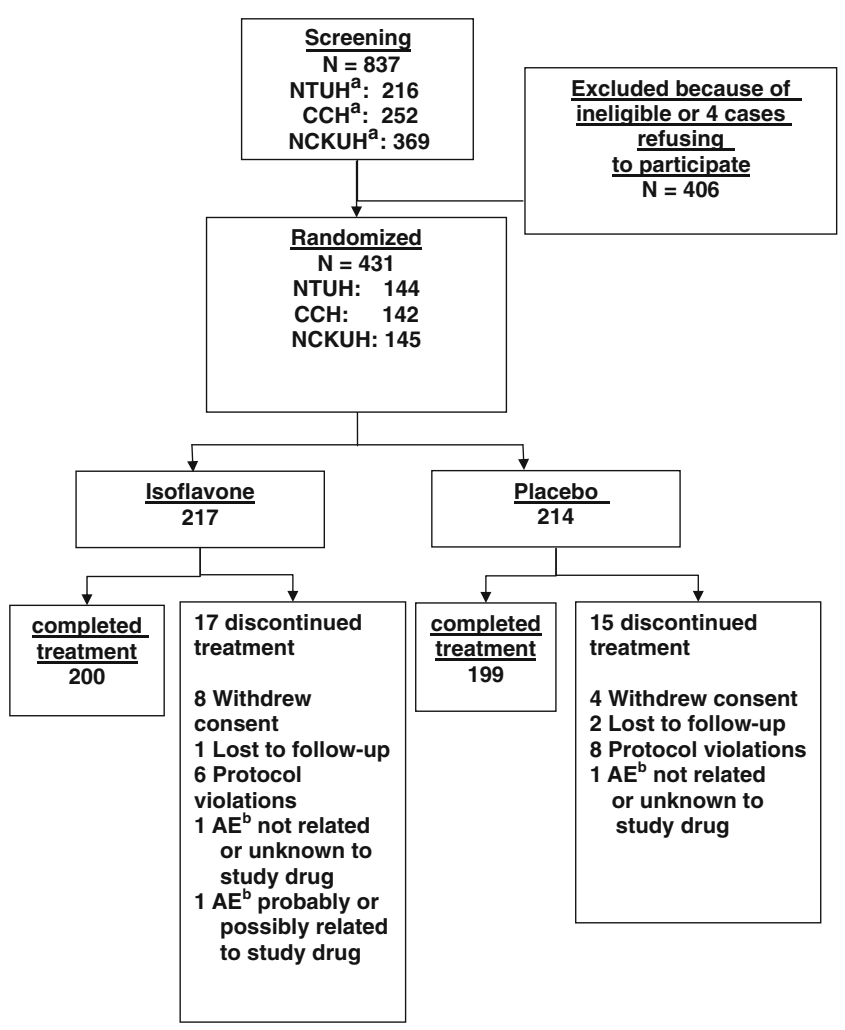

Fig. 1 Enrollment flow chart of patients. Superscript a National Taiwan University Hospital is abbreviated as NTUH, Changhua Christian Hospital as $\mathrm{CCH}$, and National Cheng Kung University Hospital as NCKUH. Superscript $b$ AE denotes adverse events according to a randomization list. An identification number was not re-allocated, if the subject was withdrawn from the study.

Study products

Each isoflavone capsule contained $50 \mathrm{mg}$ of isoflavones (aglycone equivalents) of which genistein and daidzein comprised $57.5 \%$ and $42.5 \%$, respectively, as evidenced by high performance liquid chromatography (HPLC) analysis, and the other components were microcrystalline cellulose, xylitol, and caramel. Each subject in the isoflavone group took three capsules of isoflavones twice a day. The remaining subjects took three placebo capsules twice a day. Each placebo capsule contained microcrystalline cellulose, xylitol, caramel, and soybean sauce flavor without isoflavones. The net weight of the content inside each capsule was $280 \mathrm{mg}$. The exterior of the isoflavone and placebo capsules appeared identical, and the capsules were distributed to each participant in a double-blind fashion. All participants also took a single calcium phosphate tablet, containing $300 \mathrm{mg}$ of elemental calcium and $62.5 \mathrm{IU}$ of vitamin $\mathrm{D}_{3}$ twice daily (Bio-cal ${ }^{\circledR}$, TTY Co. Ltd, Taipei, Taiwan).

\section{Laboratory tests and questionnaires}

After an overnight fast, venous blood was sampled to determine $\mathrm{HbAlc}$, plasma glucose, total cholesterol, highdensity lipoprotein cholesterol, low-density lipoprotein cholesterol, triglyceride, high sensitivity C-reactive protein, urea nitrogen, creatinine, uric acid, ALT, and AST at baseline and 4, 48, and 96 weeks. Serum bone-specific alkaline phosphatase (BAP, Beckman Access Ostase ${ }^{\circledR}$, Fullerton, CA, USA; interassay coefficient of variation $(\mathrm{CV})=14 \%$ and intraassay $\mathrm{CV}=9 \%$ ) and urine collected for routine urinalysis and $\mathrm{N}$-telopeptide of type 1 collagen (NTx, Vitros Immunodiagnostic Products, Ortho-Clinical Diagnostics, Buckinghamshire, UK; interassay $\mathrm{CV}=15 \%$ and intraassay $\mathrm{CV}=10 \%$ ) were examined at baseline and 48 and 96 weeks. Serum concentrations of isoflavone metabolites, genistein and daidzein, were analyzed at baseline and 48 and 96 weeks by HPLC in accordance with Franke et al. [16]. All biochemical assays were conducted at the certified laboratory of NTUH, except routine urinalysis at the local hospital by the staff blinded to case and placebo status. After randomization, the International Physical Activity Questionnaire-Short Form [17, 18], 24-h diet recall, and the Isoflavone Basic Diet Information Food Frequency Questionnaire $[19,20]$ were used to interview all participants at baseline and 48 and 96 weeks. Participants were requested to maintain their habitual diet and exercise patterns, which were documented by the same dietitians based on validated 
questionnaires in face-to-face interviews. We did not measure blood 25-hydroxyvitamin D [25(OH)D] level in this study.

Bone mineral density assessment

Lumbar spine (L2-L4) and right total proximal femur BMD were measured by dual-energy X-ray absorptiometry (DXA) at baseline and 24, 48, 72, and 96 weeks after randomization. The manufacturers of the DXA equipment used at the three geographic sites were Norland XR-26 Mark II (Fort Atkinson, WI, USA), Hologic QDR 4500C (Bedford, MA, USA), and GE-Lunar Prodigy (Madison, WI, USA) for NTUH, $\mathrm{CCH}$, and $\mathrm{NCKUH}$, respectively. Each instrument was subjected to a daily performance check using its specific calibrator. The day-to-day $\mathrm{CVs}$ at each site were $0.7 \%, 0.4 \%$, and $0.3 \%$, respectively. We also used a circulating phantom to examine the reproducibility of the three sets of instruments. The CVs of the repeated readings (once every 4 months, $N=7$ ) were $0.7 \%, 0.2 \%$, and $0.6 \%$ for Norland, Hologic, and Lunar instruments, respectively. The BMD of each subject was measured by the same certified technician using the same instrument throughout the entire study period. Because there had been some differences in BMD among these three instruments, the primary endpoint was used to examine the percentage change in BMD during the course of treatment. We decided to detect lumbar spine BMD at L2 to L4 level because of the software limitation of Norland XR-26 Mark II. Total proximal femur BMD data from NTUH site were also missing due to the software limitation of the Norland XR26 Mark II.

\section{Safety and adverse events}

In addition to the aforementioned laboratory tests, the safety of the participants was further monitored by conducting mammography for occult breast cancer, gynecological sonography for evaluation of endometrial thickness, pap smears for cervical dysplasia or cancer, and Xrays for vertebral fractures at baseline and 96 weeks after randomization. Adverse events were classified according to body system and the coding symbols for a thesaurus of adverse reaction terms were used [21]. Participants were asked about their symptoms at the clinics every 3 months.

\section{Compliance}

To ensure the compliance of the participants, new capsules were distributed and unused capsules retrieved every 3 months to estimate compliance rates. The compliance rate was calculated as the percentage of total taken capsules in the total dispensed capsules.
Statistical methods

Descriptive data are given as the mean (standard deviation, SD) for continuous variables and number (percent) for categorical variables. For continuous variables, differences in mean percentage changes from baseline between the two groups were evaluated by Student's $t$ test. The primary efficacy data on lumbar spine and total proximal femur BMD were examined using intention-to-treat analysis. Additionally, we used a generalized estimating equation (GEE) model to estimate the differences in values of BMD, $\mathrm{BAP}$, and NTx/creatinine at each time point between the two groups and also the time trend after treatment. A $p$ value of 0.05 or less was considered statistically significant.

\section{Results}

Baseline characteristics of study participants

The enrollment flow chart of patients is displayed in Fig. 1. Two hundred out of 217 cases and 199 out of 214 cases, respectively, in the isoflavone and placebo groups completed the treatment. The compliance rate was estimated at approximately $88 \%$. The randomization codes of 431 cases were not broken, and unblinding did not occur in any case until the conclusion of the study. As indicated in Table 1, no significant differences in terms of demographic characteristics were observed between the two groups. There were no significant differences detected at baseline in body weight, daily activity, isoflavone intake, calcium intake, total energy intake, bone turnover markers, or lumbar spine and total femur BMD. Daily physical activity, energy intake, and isoflavone intake showed no significant differences within or between groups at 48 and 96 weeks after randomization.

The efficacy of isoflavone on bone

Table 2 shows the serum concentrations of genistein and daidzein. The serum concentrations of isoflavones were remarkably elevated in the isoflavone group $(p<0.001)$. Table 3 shows the mean percentage changes $(95 \% \mathrm{CI})$ from their corresponding baseline values for lumbar spine (L2L4) and total femur BMD. The differences between the isoflavone and placebo groups were not statistically significant at any time point according to two-sample $t$ tests. Using a GEE model, the differences in mean percentage changes of BMD at lumbar spine $(p=0.42)$ and total femur $(p=0.39)$ between the isoflavone and placebo groups after controlling for time effect still depicted no significant difference, respectively. However, there was significant bone loss at the two sites in both treatment 
Table 1 Demographic characteristics in the isoflavone and placebo groups
Data are mean (SD) as continuous variable; number (percent) as categorical variable. Lumbar spine (L2-L4) and total proximal femur BMD were measured by dual-energy X-ray absorptiometry (DXA). The manufacturers of DXA equipment used at the three geographic sites are Norland XR-26 Mark II (Fort Atkinson, WI, USA), Hologic QDR 4500C (Bedford, MA, USA), and GE-Lunar Prodigy (Madison, WI, USA) for NTUH, $\mathrm{CCH}$, and $\mathrm{NCKUH}$, respectively ${ }^{\mathrm{a}} p$ value indicates difference between the isoflavone and placebo groups assessed by twosample $t$ test

${ }^{\mathrm{b}}$ There were 145 participants in the isoflavone group and 142 participants in the placebo group $B M D$ bone mineral density, METs metabolic equivalents

\begin{tabular}{|c|c|c|c|}
\hline & $\begin{array}{l}\text { Isoflavone }(N=217) \\
\text { Mean }(\mathrm{SD}) \text { or number }(\%)\end{array}$ & $\begin{array}{l}\text { Placebo }(N=214) \\
\text { Mean }(\mathrm{SD}) \text { or number }(\%)\end{array}$ & $p$ value $^{\mathrm{a}}$ \\
\hline Age (years) & $55.8(3.6)$ & $55.9(4.0)$ & 0.16 \\
\hline Weight (kg) & $54.9(5.9)$ & $54.5(7.2)$ & 0.51 \\
\hline Body mass index $\left(\mathrm{kg} / \mathrm{m}^{2}\right)$ & $23.0(2.4)$ & $22.8(2.8)$ & 0.42 \\
\hline Menopausal duration (years) & $5.0(2.7)$ & $5.1(2.6)$ & 0.59 \\
\hline \multicolumn{4}{|l|}{ History of hysterectomy } \\
\hline Yes & $28(13 \%)$ & $24(11 \%)$ & 0.59 \\
\hline \multicolumn{4}{|l|}{ Cigarette smoking } \\
\hline Past & 1 & 0 & \\
\hline \multicolumn{4}{|l|}{ Habitual alcohol consumption } \\
\hline Yes & $6(3 \%)$ & $7(3 \%)$ & 0.88 \\
\hline \multicolumn{4}{|l|}{ History of diabetes } \\
\hline Yes & $17(8 \%)$ & $16(7 \%)$ & 0.89 \\
\hline \multicolumn{4}{|l|}{ History of hypertension } \\
\hline Yes & $35(16 \%)$ & $38(18 \%)$ & 0.65 \\
\hline \multicolumn{4}{|l|}{ History of hyperlipidemia } \\
\hline Yes & $108(50 \%)$ & $96(45 \%)$ & 0.31 \\
\hline \multicolumn{4}{|l|}{ Lumbar spine BMD $\left(\mathrm{g} / \mathrm{cm}^{2}\right)$} \\
\hline NTUH & $0.808(0.081)$ & $0.815(0.095)$ & 0.63 \\
\hline $\mathrm{CCH}$ & $0.860(0.082)$ & $0.865(0.077)$ & 0.74 \\
\hline NCKUH & $0.920(0.081)$ & $0.918(0.072)$ & 0.92 \\
\hline \multicolumn{4}{|l|}{ Total proximal femur $\mathrm{BMD}^{\mathrm{b}}\left(\mathrm{g} / \mathrm{cm}^{2}\right)$} \\
\hline $\mathrm{CCH}$ & $0.795(0.084)$ & $0.772(0.089)$ & 0.12 \\
\hline NCKUH & $0.832(0.082)$ & $0.827(0.105)$ & 0.71 \\
\hline Bone alkaline phosphatase $(\mu \mathrm{g} / \mathrm{L})$ & $15.96(5.58)$ & $16.41(5.83)$ & 0.42 \\
\hline $\begin{array}{l}\text { Urinary N-telopeptide of type } 1 \\
\text { collagen/creatinine (nM BCE/ } \\
\mathrm{mM} \text { ) }\end{array}$ & $62.12(29.10)$ & $67.29(45.25)$ & 0.17 \\
\hline $\begin{array}{l}\text { Daily physical activity (total METs/ } \\
\text { week) }\end{array}$ & $4,364(2,287)$ & $4,320(2,268)$ & 0.85 \\
\hline Daily isoflavone intake (mg) & $23(21)$ & $25(28)$ & 0.37 \\
\hline Daily energy intake (kcal) & $1,535(502)$ & $1,547(512)$ & 0.82 \\
\hline Daily calcium intake (mg) & $538(340)$ & $508(367)$ & 0.11 \\
\hline
\end{tabular}

groups $(p<0.001)$. In the 2-year study period, both groups lost approximately $1.5 \%$ of spine BMD and $1.0 \%$ of total femur BMD. Because biases may persist in pooled BMD data from different instruments, we also analyzed mean percentage change from baseline lumbar spine and total femur BMD derived from each center. The result failed to reveal any significant difference between the isoflavone and placebo groups (Table 4). There was no statistically significant difference in serial percentage changes of bone markers between the two groups according to two-sample $t$ tests (Table 5). Again, using a GEE method, the difference in the serial percentage changes of BAP and urinary NTx/ creatinine from their corresponding baselines failed to show any statistical significance between the isoflavone and placebo groups ( $p=0.78$ and 0.43 , respectively).
Bone fractures

In the isoflavone group, 15 cases were reported with fractures of the clavicle (1 case), wrist (3 cases), ankle ( 2 cases), proximal femur (1 case), and vertebral bodies ( 8 cases), respectively, whereas there were 2 cases of wrist fractures and 7 cases of vertebral fractures in the placebo group. All cases with clavicle, wrist, ankle, and proximal femur fractures except one case with colles' fracture were hospitalized for a period of time and continued the clinical trial. Only the case with proximal femur fracture withdrew, because she was treated with a bisphosphonate following the fracture. The relative risk of bone fracture and its $95 \%$ CI for the isoflavone group were $1.64(0.74$, 3.67). 
Table 2 Mean (SD) of serum genistein and daidzein concentrations at each visit

$p$ value indicates difference between the isoflavone and placebo groups assessed by twosample $t$ test

\begin{tabular}{lllll}
\hline Variable and group & Baseline $(N)$ & 4 weeks $(N)$ & 48 weeks $(N)$ & 96 weeks $(N)$ \\
\hline Genistein $(\mu \mathrm{mol} / \mathrm{L})$ & & & & \\
Isoflavone & $0.34(1.26)(212)$ & $6.85(5.05)(210)$ & $4.10(4.34)(204)$ & $3.30(3.18)(200)$ \\
Placebo & $0.23(0.74)(211)$ & $0.19(0.71)(210)$ & $0.20(0.67)(203)$ & $0.24(0.80)(198)$ \\
Difference $(95 \% \mathrm{CI})$ & $0.11(-0.08,0.31)$ & $6.66(5.96,7.35)$ & $3.91(3.30,4.51)$ & $3.05(2.60,3.51)$ \\
$p$ value & 0.80 & $<0.001$ & $<0.001$ & $<0.001$ \\
Daidzein $(\mu \mathrm{mol} / \mathrm{L})$ & & & & \\
Isoflavone & $0.09(0.36)(212)$ & $1.44(1.35)(212)$ & $1.12(1.16)(204)$ & $0.73(0.92)(200)$ \\
Placebo & $0.05(0.20)(211)$ & $0.07(0.35)(211)$ & $0.10(0.48)(203)$ & $0.04(0.23)(199)$ \\
Difference $(95 \% \mathrm{CI})$ & $0.05(-0.01,0.10)$ & $1.38(1.19,1.56)$ & $1.02(0.85,1.19)$ & $0.69(0.56,0.82)$ \\
$p$ value & 0.34 & $<0.001$ & $<0.001$ & $<0.001$ \\
\hline
\end{tabular}

\section{Adverse events}

With the exception of the fractures mentioned above over the 2-year course of treatment, those cases marked by withdrawal of agreement, failure to be reached during follow-up, and protocol violation are listed in Fig. 1 . Additionally, one case in the isoflavone arm had a skin reaction (itching) and discontinued the study. The overall incidence rate of adverse events was not significantly different between the two groups.

Serious adverse events

Six serious adverse events occurred in the placebo group throughout the course (one acute myocardial infarction, one intracerebral hemorrhage, one transient ischemic attack, one head injury, and two cases of colon cancer). In the isoflavone group, one case was admitted for blood pressure control and another case underwent surgery for breast cancer. The overall incidence rate of serious adverse events was not significantly different between the two arms.

\section{Discussion}

The results of the current randomized, double-blind, placebo-controlled study indicated that a daily intake of 300-mg isoflavones (aglycone equivalents) for 2 years generated no difference in the rate of bone loss at the lumbar spine or total femur. The two bone turnover markers examined, serum BAP and urinary NTx/creatinine, similarly showed no significant difference between the two groups throughout the course of treatment. In terms of time trend, isoflavone treatment in this study failed to change bone

Table 3 Mean percentage changes (SD) of BMD from baseline in lumbar spine and total proximal femur in the isoflavone and placebo groups at each visit

\begin{tabular}{|c|c|c|c|c|c|c|c|}
\hline Measurement & $\begin{array}{l}\text { Follow-up } \\
\text { (weeks) }\end{array}$ & $\begin{array}{l}\text { Isoflavone } \\
\text { Mean percentage } \\
\text { change (SD) }(N)\end{array}$ & $\begin{array}{l}\text { Placebo } \\
\text { Mean percentage } \\
\text { change (SD) }(N)\end{array}$ & $\begin{array}{l}\text { Difference } \\
\text { Mean }(95 \% \mathrm{CI})\end{array}$ & $p$ value $^{\mathrm{a}}$ & $p$ value $^{\mathrm{b}}$ & $\begin{array}{l}p \text { value for } \\
\text { time trend }^{\mathrm{C}}\end{array}$ \\
\hline \multirow[t]{3}{*}{ Lumbar spine } & $\begin{array}{l}24 \\
48\end{array}$ & $\begin{array}{r}0.24(3.25)(205) \\
-0.29(3.12)(202)\end{array}$ & $\begin{array}{l}-0.04(3.14)(205) \\
-0.55(3.52)\end{array}$ & $\begin{array}{l}0.27(-0.35,0.89) \\
0.26(-0.39,0.91)\end{array}$ & $\begin{array}{l}0.38 \\
0.43\end{array}$ & \multirow[t]{3}{*}{0.42} & \multirow[t]{3}{*}{$<0.001$} \\
\hline & 72 & $-1.14(3.58)(200)$ & $-0.92(3.96)(199)$ & $-0.23(-0.97,0.52)$ & 0.55 & & \\
\hline & 96 & $-1.09(3.95)(200)$ & $-1.72(4.12)(199)$ & $0.63(-0.17,1.42)$ & 0.12 & & \\
\hline \multirow[t]{3}{*}{$\begin{array}{l}\text { Total proximal } \\
\text { femur }\end{array}$} & $\begin{array}{l}24 \\
48\end{array}$ & $\begin{array}{l}-0.02(2.63)(136) \\
-0.0004(2.93)(133)\end{array}$ & $\begin{array}{l}-0.13(2.43)(136) \\
-0.40(2.72)(133)\end{array}$ & $\begin{array}{l}0.11(-0.49,0.71) \\
0.40(-0.28,1.08)\end{array}$ & $\begin{array}{l}0.72 \\
0.25\end{array}$ & \multirow[t]{3}{*}{0.39} & \multirow[t]{3}{*}{$<0.001$} \\
\hline & 72 & $-0.13(3.31)(129)$ & $-0.12(3.85)(130)$ & $-0.004(-0.88,0.88)$ & 0.99 & & \\
\hline & 96 & $-0.81(3.59)(133)$ & $-1.35(2.67)(132)$ & $0.54(-0.23,1.30)$ & 0.17 & & \\
\hline
\end{tabular}

${ }^{\mathrm{a}} p$ value denotes the comparison of mean percentage changes from respective baseline between the isoflavone and placebo groups by two-sample $t$ test

${ }^{\mathrm{b}} p$ value indicates the comparison of mean percentage change from respective baseline between the isoflavone and placebo groups using the generalized estimating equation (GEE) methods to control for time effect in the repeated measurement

${ }^{c} p$ value for time trend denotes the repeated measurement of time trend in the GEE model

$B M D$ bone mineral density 
Table 4 Mean percentage changes (SD) of BMD from baseline in lumbar spine and total proximal femur in the isoflavone and placebo groups at each visit

\begin{tabular}{|c|c|c|c|c|c|c|c|}
\hline Measurement & $\begin{array}{l}\text { Follow-up } \\
\text { (weeks) }\end{array}$ & $\begin{array}{l}\text { Isoflavone } \\
\text { Mean percentage } \\
\text { change (SD) }(N)\end{array}$ & $\begin{array}{l}\text { Placebo } \\
\text { Mean percentage } \\
\text { change }(\mathrm{SD})(N)\end{array}$ & $\begin{array}{l}\text { Difference } \\
\text { Mean }(95 \% \mathrm{CI})\end{array}$ & $p$ value $^{\mathrm{a}}$ & $p$ value $^{\mathrm{b}}$ & $\begin{array}{l}p \text { value for } \\
\text { time trend }\end{array}$ \\
\hline \multicolumn{8}{|l|}{ Lumbar spine } \\
\hline \multirow[t]{3}{*}{ NTUH } & $\begin{array}{l}24 \\
48\end{array}$ & $\begin{array}{l}-0.14(3.56)(68) \\
-0.12(3.58)(67)\end{array}$ & $\begin{array}{l}-0.21(3.40)(68) \\
-0.22(3.58)(66)\end{array}$ & $\begin{array}{l}0.07(-1.11,1.26) \\
0.10(-1.13,1.32)\end{array}$ & $\begin{array}{l}0.90 \\
0.88\end{array}$ & \multirow[t]{3}{*}{0.65} & \multirow[t]{3}{*}{0.001} \\
\hline & 72 & $-0.96(3.75)(66)$ & $-0.22(4.31)(66)$ & $-0.73(-2.12,0.66)$ & 0.30 & & \\
\hline & 96 & $-1.04(4.18)(67)$ & $-1.13(4.49)(66)$ & $0.09(-1.40,1.57)$ & 0.91 & & \\
\hline \multirow[t]{3}{*}{$\mathrm{CCH}$} & $\begin{array}{l}24 \\
48\end{array}$ & $\begin{array}{r}0.18(3.20)(70) \\
-0.64(2.53)(69)\end{array}$ & $\begin{array}{l}-0.12(2.39)(65) \\
-1.27(3.12)(63)\end{array}$ & $\begin{array}{l}0.30(-0.67,1.26) \\
0.63(-0.35,1.62)\end{array}$ & $\begin{array}{l}0.55 \\
0.21\end{array}$ & \multirow[t]{3}{*}{0.79} & \multirow[t]{3}{*}{0.001} \\
\hline & 72 & $-2.16(3.02)(68)$ & $-1.64(3.50)(63)$ & $-0.52(-1.64,0.61)$ & 0.37 & & \\
\hline & 96 & $-1.81(3.41)(68)$ & $-2.43(3.47)(63)$ & $0.62(-0.57,1.81)$ & 0.30 & & \\
\hline \multirow[t]{3}{*}{ NCKUH } & $\begin{array}{l}24 \\
48\end{array}$ & $\begin{array}{r}0.68(2.94)(67) \\
-0.08(3.19)(66)\end{array}$ & $\begin{array}{r}0.20(3.50)(72) \\
-0.21(3.75)(70)\end{array}$ & $\begin{array}{l}0.48(-0.61,1.57) \\
0.12(-1.06,1.31)\end{array}$ & $\begin{array}{l}0.39 \\
0.84\end{array}$ & \multirow[t]{3}{*}{0.62} & \multirow[t]{3}{*}{$<0.001$} \\
\hline & 72 & $-0.29(3.71)(66)$ & $-0.92(3.94)(70)$ & $0.63(-0.67,1.93)$ & 0.34 & & \\
\hline & 96 & $-0.40(4.15)(65)$ & $-1.64(4.26)(70)$ & $1.24(-0.19,2.67)$ & 0.09 & & \\
\hline \multicolumn{8}{|c|}{ Total proximal femur } \\
\hline \multirow[t]{3}{*}{$\mathrm{CCH}$} & $\begin{array}{l}24 \\
48\end{array}$ & $\begin{array}{r}-0.25(3.12)(69) \\
0.09(3.65)(68)\end{array}$ & $\begin{array}{l}-0.32(3.05)(64) \\
-0.79(3.42)(63)\end{array}$ & $\begin{array}{l}0.07(-0.98,1.13) \\
0.87(-0.35,2.10)\end{array}$ & $\begin{array}{l}0.89 \\
0.16\end{array}$ & \multirow[t]{3}{*}{0.06} & \multirow[t]{3}{*}{0.001} \\
\hline & 72 & $0.39(4.16)(64)$ & $0.004(5.29)(60)$ & $0.39(-1.30,2.07)$ & 0.65 & & \\
\hline & 96 & $-1.10(4.12)(68)$ & $-2.12(2.85)(62)$ & $1.03(-0.19,2.25)$ & 0.10 & & \\
\hline \multirow[t]{3}{*}{ NCKUH } & $\begin{array}{l}24 \\
48\end{array}$ & $\begin{array}{r}0.21(2.00)(67) \\
-0.09(1.92)(65)\end{array}$ & $\begin{array}{r}0.04(1.70)(72) \\
-0.05(1.85)(70)\end{array}$ & $\begin{array}{r}0.17(-0.45,0.79) \\
-0.04(-0.68,0.60)\end{array}$ & $\begin{array}{l}0.59 \\
0.90\end{array}$ & \multirow[t]{3}{*}{0.71} & \multirow[t]{3}{*}{0.001} \\
\hline & 72 & $-0.63(2.09)(65)$ & $-0.23(1.94)(70)$ & $-0.41(-1.09,0.28)$ & 0.24 & & \\
\hline & 96 & $-0.51(2.95)(65)$ & $-0.66(2.32)(70)$ & $0.15(-0.75,1.05)$ & 0.74 & & \\
\hline
\end{tabular}

${ }^{\mathrm{a}} p$ value denotes the comparison of percentage changes from respective baseline between the isoflavone and placebo groups by two-sample $t$ test ${ }^{\mathrm{b}} p$ value indicates the comparison of mean percentage change from respective baseline between the isoflavone and placebo groups using the generalized estimating equation (GEE) methods to control for time effect in the repeated measurement

${ }^{\mathrm{c}} p$ value for time trend denotes the repeated measurement of time trend in GEE model

$B M D$ bone mineral density

turnover biomarkers and failed to prevent lumbar spine or total femur BMD from declining (Tables 3, 4, and 5). Additionally, the examined serum genistein and daidzein concentrations testified to the high compliance of participants as well as the high bioavailability of isoflavones.
Unlike the results in this study, several previous studies $[8-12,22,23]$ and two meta-analyses [24, 25] showed a number of beneficial effects of soy isoflavones on bone. Most of them included only small sample sizes ( $\leqq 175$ subjects) and may have been biases, or short follow-up

Table 5 Mean percentage changes (SD) of serum bone alkaline phosphatase (BAP) and urinary N-telopeptide/creatinine (NTx/Cr) from baseline in the isoflavone and placebo groups at each visit

\begin{tabular}{|c|c|c|c|c|c|c|}
\hline Measurement & $\begin{array}{l}\text { Follow-up } \\
\text { (weeks) }\end{array}$ & $\begin{array}{l}\text { Isoflavone } \\
\text { Mean percentage } \\
\text { change (SD) }(N)\end{array}$ & $\begin{array}{l}\text { Placebo } \\
\text { Mean percentage } \\
\text { change }(\mathrm{SD})(N)\end{array}$ & $\begin{array}{l}\text { Difference } \\
\text { Mean }(95 \% \mathrm{CI})\end{array}$ & $p$ value $^{\mathrm{a}}$ & $p$ value $^{\mathrm{b}}$ \\
\hline $\begin{array}{l}\text { Serum bone alkaline phosphatase } \\
(\mathrm{BAP}, \mu \mathrm{g} / \mathrm{L})\end{array}$ & $\begin{array}{l}48 \\
96\end{array}$ & $\begin{array}{l}-4.42(29.13)(201) \\
-1.98(28.56)(199)\end{array}$ & $\begin{array}{l}-3.64(39.10)(200) \\
-4.23(28.82)(199)\end{array}$ & $\begin{array}{r}-0.78(-7.55,5.99) \\
2.24(-3.41,7.90)\end{array}$ & $\begin{array}{l}0.82 \\
0.44\end{array}$ & 0.78 \\
\hline $\begin{array}{l}\text { Urinary N-telopeptide/creatinine } \\
\text { (NTx/Cr, nM BCE/mM) }\end{array}$ & $\begin{array}{l}48 \\
96\end{array}$ & $\begin{array}{r}12.80(47.04)(201) \\
9.01(50.08)(198)\end{array}$ & $\begin{array}{r}10.53(58.71)(199) \\
3.23(66.22)(198)\end{array}$ & $\begin{array}{l}2.26(-8.19,12.72) \\
5.77(-5.82,17.37)\end{array}$ & $\begin{array}{l}0.67 \\
0.33\end{array}$ & 0.43 \\
\hline
\end{tabular}

${ }^{\mathrm{a}} p$ value denotes the comparison of changes from respective baseline between the isoflavone and placebo groups by two-sample $t$ test

${ }^{\mathrm{b}} p$ value indicates the comparison of mean change from respective baseline between the isoflavone and placebo groups using the generalized estimating equation (GEE) methods to control for time effect in the repeated measurement

$B A P$ bone-specific alkaline phosphatase, $N T x / C r$ N-telopeptide/creatinine 
periods ( $\leqq 12$ months), so that true long-term effects could not be assessed, and most of these studies did not measure the serum levels of isoflavones. The two recent metaanalyses (both by Taku et al.) analyzed the overall effects of soy isoflavone supplements on bone turnover markers and BMD separately [24, 25]. There was only a modest overall decrease of urinary deoxypyridinoline, whereas the other bone turnover markers including osteocalcin, BAP, and other bone resorption markers did not show a significant change [24]. Meta-analysis on the effects of supplementation with soy isoflavone extract with an average of 82 (47150) $\mathrm{mg}$ (aglycone equivalents) on BMD showed an increase in lumbar spine BMD by $2.4 \%$ after 6 to 12 months. However, no significant change of proximal femur BMD could be found [25]. Taken together, these results were different from those of conventional estrogen therapy, making it difficult to obtain a clear picture of the mechanism behind the action of isoflavone, a phytoestrogen, on bones. On the other hand, several recent reports have demonstrated the absence of beneficial effects of isoflavones on bone [26-34], supporting our findings. This controversy may be the result of differences in dosage, product forms, length of observations, ethnic dietary habits, or other factors. To further complicate the issue, a number of reports have claimed antagonistic activities of various isoflavones [35], or the need for the presence of soy protein for isoflavones to exert their effects on BMD [8, 36, 37]. For example, Morabito et al. and Marini et al. reported that the ingestion of single isoflavone-genistein $54 \mathrm{mg}$ /day for 1 [10] and 2 years [23] resulted in a decline of bone resorption markers and an increase in bone formation markers and BMD of the lumbar spine and femoral neck. These outcomes were totally different from ours. Because each subject in the isoflavone arm of the current study consumed $172.5-\mathrm{mg}$ genistein and $127.5 \mathrm{-mg}$ daidzein/day, whether the discrepancy between our results and those of aforementioned authors is due to the antagonistic activities of various isoflavones requires further clarification. We administered a relatively large dose of a common aglycone combination $(57.5 \%$ genistein and $42.5 \%$ daidzein, without soy protein) and measured bone turnover markers and BMD both at the lumbar spine and proximal femur every 6 months. Our results did not show any significant effects throughout the 24 months, in the presence of markedly elevated serum levels of genistein and diadzein of the isoflavone-treated group. Thus, our results strongly suggest that soy isoflavones in the form and dosage used in this study have no transient or long-term effect on bone in postmenopausal women.

One of the participants in the isoflavone arm was diagnosed with breast cancer in the study period. According to the statistics of Taiwan Cancer Registry, Department of Health, Executive Yuan for the year 2006, the incidence rate of breast cancer in the entire female population aged 45 64 years in Taiwan was 141.9/100,000 person-year, which was apparently lower than the incidence rate of breast cancer in the isoflavone group of this study $(230.4 / 100,000$ person-year). This subject was treated with estrogen and progesterone for 3-4 years after menopause and discontinued for more than 1 year prior to randomization in this study. The breast cancer of this subject might be incidental, and the causal relationship remains unclear.

This study may have shortcomings. (1) The baseline serum levels of genistein and daidzein were higher than those reported in the Caucasian population [31, 38], which may mask the effects of the supplement. Nonetheless, the baseline levels were far lower than the post-treatment levels of the isoflavone-treated subjects, making this possibility less likely. (2) The supplement of vitamin D (125 IU of vitamin $\mathrm{D}_{3}$ daily) in this study may have been suboptimal. We did not measure plasma 25(OH)D level in this study. Consequently, the possibility of vitamin D deficiency or insufficiency and their impact on the effects of isoflavones could not be completely ruled out. However, all our participants were ambulatory. A previous study on the nutritional status of vitamin D among ambulatory women aged 40 to 75 of Taipei City reported that vitamin D deficiency was very rare [39], and it was further supported by the report that dietary vitamin $\mathrm{D}$ intakes were relatively adequate in this population [40]. Thus, vitamin D insufficiency or deficiency may not have been a major factor for the lack of effects of isoflavones. (3) We did not collect data on hot flashes that could have served as a reflection of the biological effect and the appropriateness of the dosage of the isoflavones used in this study, in addition to the serum levels of isoflavones. (4) We used three different models of instruments from three different manufacturers to measure BMD. The variations among the three instruments may have masked the effects of soy isoflavones. However, we performed BMD measurements according to the International Society of Clinical Densitometry guidelines. The instruments had daily quality checks and were operated by the same technologists throughout the period of study. The results within each center were analyzed separately and did not show any trend of effects. (5) A lack of total proximal femur BMD data from one center may have reduced the power to estimate the effect of soy isoflavones. However, it is difficult to perceive how isoflavone treatment could improve proximal femur BMD while providing no benefit in preventing bone loss at the lumbar spine. (6) Our sample size was not sufficient to analyze the effects of soy isoflavone on fracture rates. The fracture incidence in our study appeared higher than the results reported by a prospective study in Shanghai, China [41]. It should be noted that our study included only osteopenic or osteoporotic women, whereas the study in Shanghai included a 
cohort from the general population. However, in view of $64 \%$ increase in bone fracture rate in the isoflavone arm compared with that of the placebo arm, more cautious monitoring in this regard is warranted in the future studies.

\section{Conclusions}

The current double-blind, randomized, placebo-controlled study of soy-extracted isoflavones on bone health failed to detect either an antiresorptive or a bone-sparing effect, despite possessing the strengths of larger dose, long observation period, and high compliance rate.

Acknowledgments We would like to thank the three local hospitals, National Taiwan University Hospital, Changhua Christian Hospital, and Cheng Kung University Hospital, for their support in clinical observation and laboratory tests; we also appreciate the assistance of Taiwan Biotech Co. Ltd, Taiwan for its generous provision of isoflavones. Additionally, the authors are grateful for all the subjects who participated in this study.

Grand support This study was supported by GE-PP02 grant "A Taiwan Isoflavone Multicenter Study (TIMS)" from the National Health Research Institutes, Zhunan, Taiwan. The funding source supervised the design, conduct, management and analysis, but was not involved in the interpretation of the study result

\section{Conflicts of interest None.}

Open Access This article is distributed under the terms of the Creative Commons Attribution Noncommercial License which permits any noncommercial use, distribution, and reproduction in any medium, provided the original author(s) and source are credited.

\section{References}

1. Torgerson DJ, Bell-Syer SE (2001) Hormone replacement therapy and prevention of vertebral fractures: a meta-analysis of randomised trials. BMC Musculoskelet Disord 2:7

2. Torgerson DJ, Bell-Syer SE (2001) Hormone replacement therapy and prevention of nonvertebral fractures: a meta-analysis of randomized trials. JAMA 285:2891-2897

3. Rossouw JE, Anderson GL, Prentice RL, LaCroix AZ, Kooperberg C, Stefanick ML, Jackson RD, Beresford SA, Howard BV, Johnson KC, Kotchen JM, Ockene J (2002) Risks and benefits of estrogen plus progestin in healthy postmenopausal women: principal results from the Women's Health Initiative randomized controlled trial. JAMA 288:321-333

4. Anderson GL, Limacher M, Assaf AR, Bassford T, Beresford SA, Black H, Bonds D, Brunner R, Brzyski R, Caan B, Chlebowski R, Curb D, Gass M, Hays J, Heiss G, Hendrix S, Howard BV, Hsia J, Hubbell A, Jackson R, Johnson KC, Judd H, Kotchen JM, Kuller L, LaCroix AZ, Lane D, Langer RD, Lasser N, Lewis CE, Manson J, Margolis K, Ockene J, O’Sullivan MJ, Phillips L, Prentice RL, Ritenbaugh C, Robbins J, Rossouw JE, Sarto G, Stefanick ML, Van Horn L, Wactawski-Wende J, Wallace R, Wassertheil-Smoller S (2004) Effects of conjugated equine estrogen in postmenopausal women with hysterectomy: the Women's Health Initiative randomized controlled trial. JAMA 291:1701-1712

5. Miksicek RJ (1994) Interaction of naturally occurring nonsteroidal estrogens with expressed recombinant human estrogen receptor. J Steroid Biochem Mol Biol 49:153-160

6. Zava DT, Duwe G (1997) Estrogenic and antiproliferative properties of genistein and other flavonoids in human breast cancer cells in vitro. Nutr Cancer 27:31-40

7. Brandi ML (1997) Natural and synthetic isoflavones in the prevention and treatment of chronic diseases. Calcif Tissue Int 61(Suppl 1):S5-S8

8. Potter SM, Baum JA, Teng H, Stillman RJ, Shay NF, Erdman JW $\mathrm{Jr}$ (1998) Soy protein and isoflavones: their effects on blood lipids and bone density in postmenopausal women. Am J Clin Nutr 68:1375S-1379S

9. Alekel DL, Germain AS, Peterson CT, Hanson KB, Stewart JW, Toda T (2000) Isoflavone-rich soy protein isolate attenuates bone loss in the lumbar spine of perimenopausal women. Am J Clin Nutr 72:844-852

10. Morabito N, Crisafulli A, Vergara C, Gaudio A, Lasco A, Frisina N, D'Anna R, Corrado F, Pizzoleo MA, Cincotta M, Altavilla D, Ientile R, Squadrito F (2002) Effects of genistein and hormonereplacement therapy on bone loss in early postmenopausal women: a randomized double-blind placebo-controlled study. J Bone Miner Res 17:1904-1912

11. Chen YM, Ho SC, Lam SS, Ho SS, Woo JL (2003) Soy isoflavones have a favorable effect on bone loss in Chinese postmenopausal women with lower bone mass: a double-blind, randomized, controlled trial. J Clin Endocrinol Metab 88:4740 4747

12. Dalais FS, Ebeling PR, Kotsopoulos D, McGrath BP, Teede HJ (2003) The effects of soy protein containing isoflavones on lipids and indices of bone resorption in postmenopausal women. Clin Endocrinol (Oxf) 58:704-709

13. Kotsopoulos D, Dalais FS, Liang YL, McGrath BP, Teede HJ (2000) The effects of soy protein containing phytoestrogens on menopausal symptoms in postmenopausal women. Climacteric 3:161-167

14. Quella SK, Loprinzi CL, Barton DL, Knost JA, Sloan JA, LaVasseur BI, Swan D, Krupp KR, Miller KD, Novotny PJ (2000) Evaluation of soy phytoestrogens for the treatment of hot flashes in breast cancer survivors: a North Central Cancer Treatment Group Trial. J Clin Oncol 18:1068-1074

15. Nikander E, Kilkkinen A, Metsa-Heikkila M, Adlercreutz H, Pietinen P, Tiitinen A, Ylikorkala O (2003) A randomized placebo-controlled crossover trial with phytoestrogens in treatment of menopause in breast cancer patients. Obstet Gynecol 101:1213-1220

16. Franke AA, Custer LJ, Wang W, Shi CY (1998) HPLC analysis of isoflavonoids and other phenolic agents from foods and from human fluids. Proc Soc Exp Biol Med 217:263-273

17. Booth M (2000) Assessment of physical activity: an international perspective. Res Q Exerc Sport 71:S114-S120

18. Liu YM (2004) Validation of the Taiwan International Physical Activity Questionnaire-Short Form (Doctoral Dissertation in Chinese), in Institute of Nursing, National Taiwan University, Taipei, Taiwan

19. Hsu HF, Chang CL, Chu YH (2000) Flavonoids amounts and antioxidant analysis in several vegetables. Taiwanese J Agric Chem Food Sci 38:377-387

20. Liu SW (2003) Validation of a food frequency questionnaire estimating flavonoids, isoflavones and carotenoids intake among elderly population. (Master Dissertation in Chinese). In Institute of Nutritional Science, Fu-Jen Catholic University, Taipei, Taiwan 
21. US Food and Drug Administration, Center for Drug Evaluation and Research (1993) Coding symbols for thesaurus of adverse reaction terms (COSTART), 4th edn. US Food and Drug Administration, Rockville

22. Xin Y, Yang HY (2006) Influence of daidzein tablets on climacteric syndrome and bone mineral density of women. Chin J Osteoporos 12:149-151

23. Marini H, Minutoli L, Polito F, Bitto A, Altavilla D, Atteritano M, Gaudio A, Mazzaferro S, Frisina A, Frisina N, Lubrano C, Bonaiuto M, D'Anna R, Cannata ML, Corrado F, Adamo EB, Wilson S, Squadrito F (2007) Effects of the phytoestrogen genistein on bone metabolism in osteopenic postmenopausal women: a randomized trial. Ann Intern Med 146:839-847

24. Taku K, Melby MK, Kurzer MS, Mizuno S, Watanabe S, Ishimi Y (2010) Effects of soy isoflavone supplements on bone turnover markers in menopausal women: systematic review and metaanalysis of randomized controlled trials. Bone 47:413-423

25. Taku K, Melby MK, Takebayashi J, Mizuno S, Ishimi Y, Omori T, Watanabe S (2010) Effect of soy isoflavone extract supplements on bone mineral density in menopausal women: meta-analysis of randomized controlled trials. Asia Pac J Clin Nutr 19:33-42

26. Gallagher JC, Satpathy R, Rafferty K, Haynatzka V (2004) The effect of soy protein isolate on bone metabolism. Menopause 11:290-298

27. Kreijkamp-Kaspers S, Kok L, Grobbee DE, de Haan EH, Aleman A, Lampe JW, van der Schouw YT (2004) Effect of soy protein containing isoflavones on cognitive function, bone mineral density, and plasma lipids in postmenopausal women: a randomized controlled trial. JAMA 292:65-74

28. Arjmandi BH, Lucas EA, Khalil DA, Devareddy L, Smith BJ, McDonald J, Arquitt AB, Payton ME, Mason C (2005) One year soy protein supplementation has positive effects on bone formation markers but not bone density in postmenopausal women. Nutr J 4:8

29. Wu J, Oka J, Tabata I, Higuchi M, Toda T, Fuku N, Ezaki J, Sugiyama F, Uchiyama S, Yamada K, Ishimi Y (2006) Effects of isoflavone and exercise on BMD and fat mass in postmenopausal Japanese women: a 1-year randomized placebo-controlled trial. J Bone Miner Res 21:780-789

30. Evans EM, Racette SB, Van Pelt RE, Peterson LR, Villareal DT (2007) Effects of soy protein isolate and moderate exercise on bone turnover and bone mineral density in postmenopausal women. Menopause 14:481-488
31. Brink E, Coxam V, Robins S, Wahala K, Cassidy A, Branca F (2008) Long-term consumption of isoflavone-enriched foods does not affect bone mineral density, bone metabolism, or hormonal status in early postmenopausal women: a randomized, double-blind, placebo controlled study. Am J Clin Nutr 87:761-770

32. Kenny AM, Mangano KM, Abourizk RH, Bruno RS, Anamani DE, Kleppinger A, Walsh SJ, Prestwood KM, Kerstetter JE (2009) Soy proteins and isoflavones affect bone mineral density in older women: a randomized controlled trial. Am J Clin Nutr 90:234242

33. Vupadhyayula PM, Gallagher JC, Templin T, Logsdon SM, Smith LM (2009) Effects of soy protein isolate on bone mineral density and physical performance indices in postmenopausal women-a 2-year randomized, double-blind, placebo-controlled trial. Menopause $16: 320-328$

34. Alekel DL, Van Loan MD, Koehler KJ, Hanson LN, Stewart JW, Hanson KB, Kurzer MS, Peterson CT (2010) The soy isoflavones for reducing bone loss (SIRBL) study: a 3-y randomized controlled trial in postmenopausal women. Am J Clin Nutr 91:218-230

35. Weaver CM, Cheong JM (2005) Soy isoflavones and bone health: the relationship is still unclear. J Nutr 135:1243-1247

36. Lydeking-Olsen E, Beck-Jensen JE, Setchell KD, Holm-Jensen T (2004) Soymilk or progesterone for prevention of bone loss-a 2 year randomized, placebo-controlled trial. Eur J Nutr 43:246257

37. Newton KM, LaCroix AZ, Levy L, Li SS, Qu P, Potter JD, Lampe JW (2006) Soy protein and bone mineral density in older men and women: a randomized trial. Maturitas 55:270-277

38. Whitten PL, Patisaul HB (2001) Cross-species and interassay comparisons of phytoestrogen action. Environ Health Perspect 109(Suppl 1):5-20

39. Tsai KS, Hsu SH, Cheng JP, Yang RS (1997) Vitamin D stores of urban women in Taipei: effect on bone density and bone turnover, and seasonal variation. Bone 20:371-374

40. Lee MS, Li HL, Hung TH, Chang HY, Yang FL, Wahlqvist ML (2008) Vitamin D intake and its food sources in Taiwanese. Asia Pac J Clin Nutr 17:397-407

41. Zhang X, Shu XO, Li H, Yang G, Li Q, Gao YT, Zheng W (2005) Prospective cohort study of soy food consumption and risk of bone fracture among postmenopausal women. Arch Intern Med $165: 1890-1895$ 